\title{
UNIVERSITY OF WYOMING OUTDOOR STUDIO ART CLASS
}

\section{INSTRUCTOR $\uparrow$ PATRICK KIKUT $\uparrow$ UNIVERSITY OF WYOMING $\uparrow$ LARAMIE}

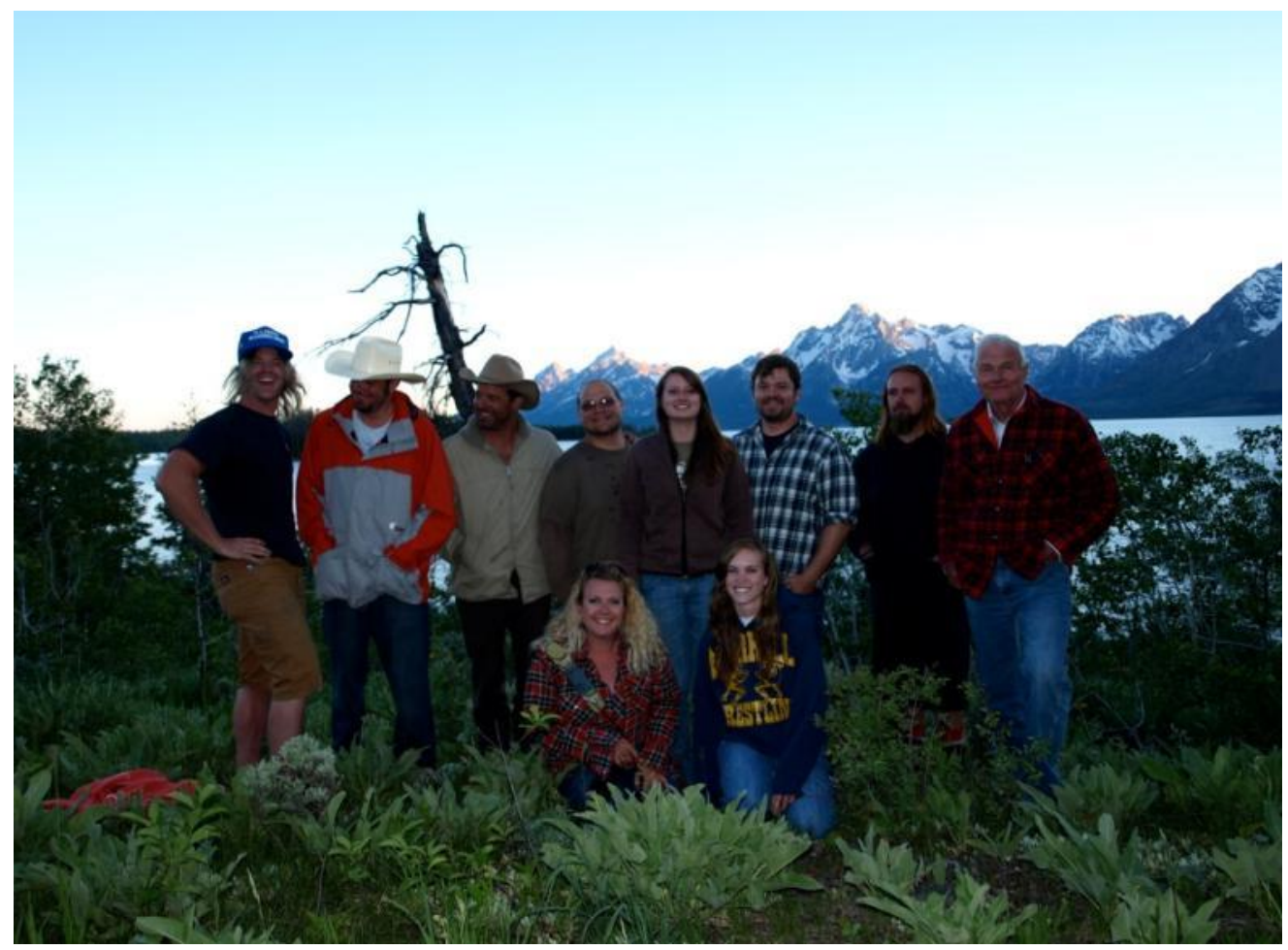

Students and faculty of the UW Art Program.

\section{$\uparrow \quad$ Class OVERVIEW}

Since its inception as a Summer Innovative Course in 2000, the Department of Art Summer Outdoor Studio class has been exceptionally grateful for the opportunity to stay and work at the AMK Research Station as part of the three week summer intensive. For art students, the dramatic setting and accommodation are inspiring and it is a highlight of the experience. From the AMK Ranch, students have full access to the Teton NP, Yellowstone NP as well as the National Wildlife Museum in Jackson. Art students also appreciate the interaction with students from different disciplines in the sciences and often those conversations have direct impact on the creative work student's produce during their stay. The AMK staff and in particular Professor Hank Harlow have offered us incredible hospitality and generosity. Professor Harlow's knowledge of the geology, biology, and history of Teton National Park is invaluable to this course. Also, his enthusiasm for art and scientific research is infectious. Our stay at the AMK always culminates in an exhibition of student and faculty creative work, hosted by Hank Harlow, UW NPS Research Station Director. 


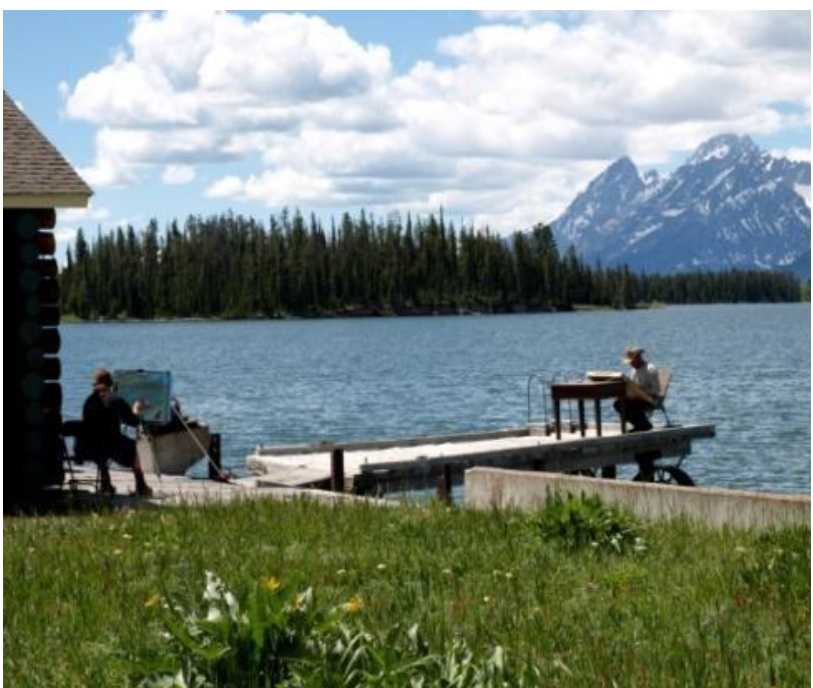

Views from the Boathouse and dock.

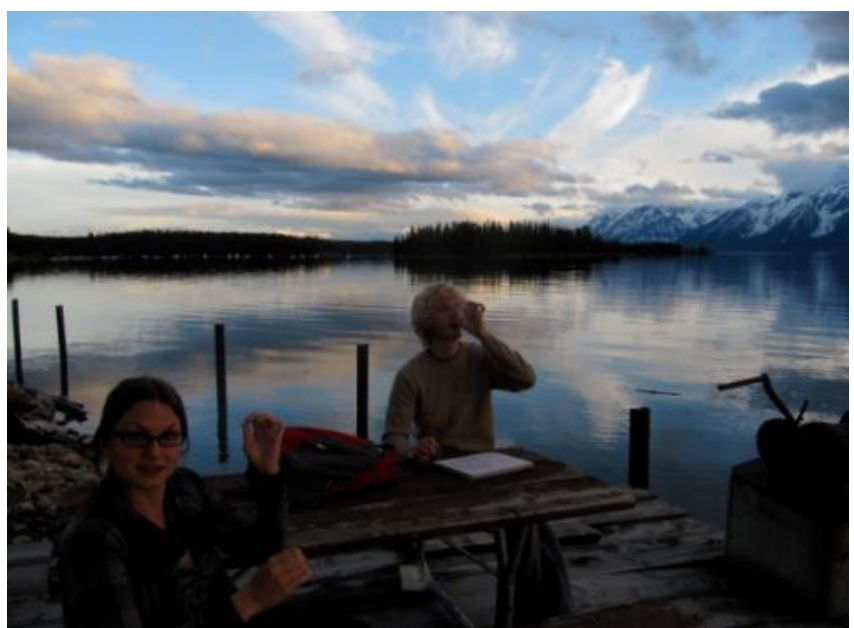

Students taking inspiration from the boat dock.

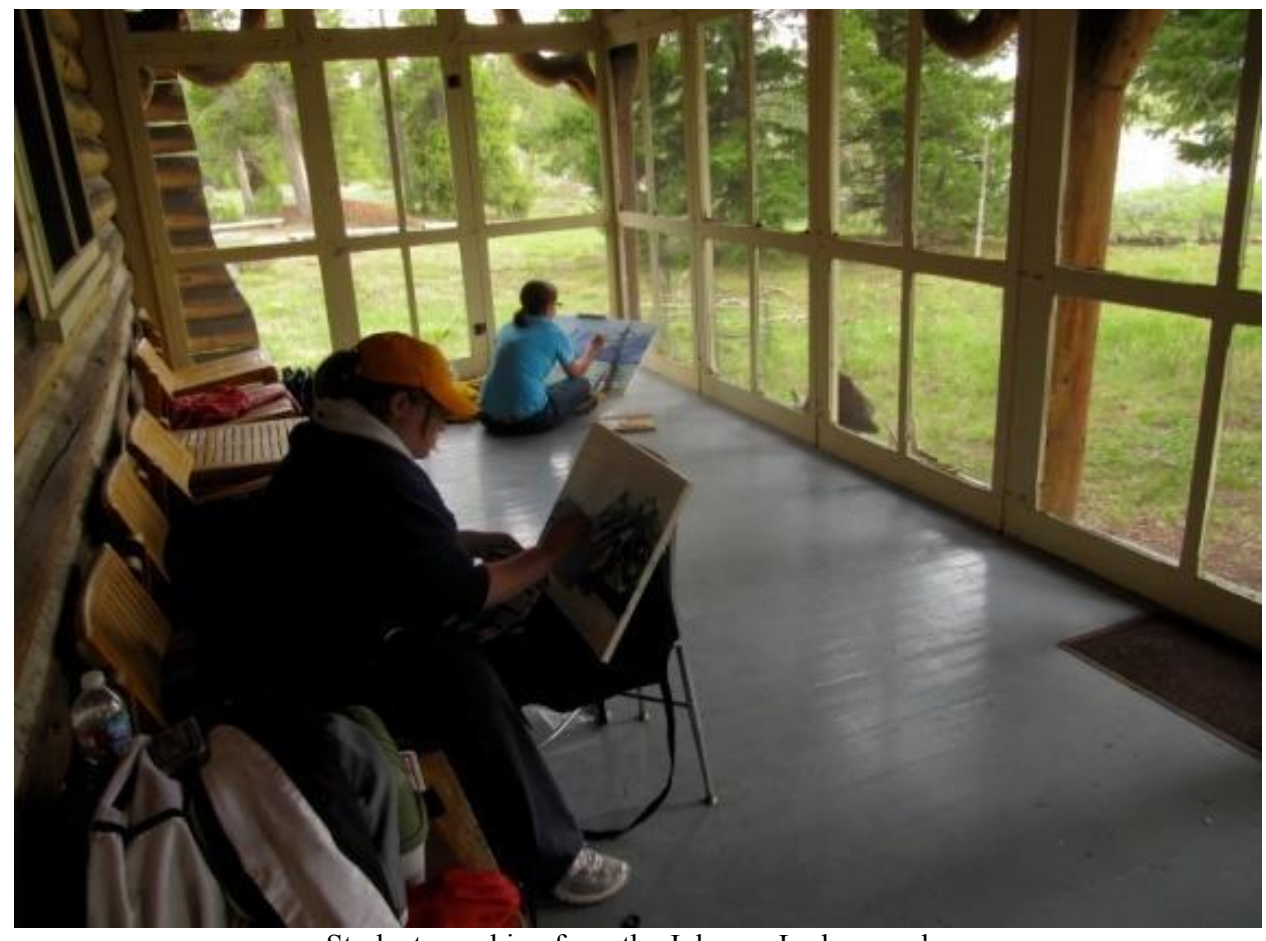

Students working from the Johnson Lodge porch. 